\title{
A variação dos custos em indústrias alimentícias listadas na BOVESPA
}

\author{
LucasGrilhocbCauto Mestrando em Administração Pública pela Universidade Federal de Alfenas. Centro Universitário de \\ Formiga (UNIFOR-MG) - Brasil. lucascarrilho@yahoo.com.br \\ DavidMaiaDaiveira Especialista em Gestão Financeira. Centro Universitário de Formiga (UNIFOR-MG) - Brasil. \\ davidmaia25@yahoo.com.br \\ Mrialsabe Mesias Graduada em Ciências Contábeis. Centro Universitário de Formiga (UNIFOR-MG) - Brasil. \\ isabelmessias10@gmail.com \\ FabílaFemencesMeneses Graduada em Ciências Contábeis. Centro Universitário de Formiga (UNIFOR-MG) - Brasil. \\ fabiulaf.meneses@hotmail.com
}

\begin{abstract}
RESUMO
Este trabalho teve como finalidade demonstrar a variação dos custos em indústrias alimentícias listadas na Bolsa de Valores de São Paulo (BOVESPA), e de que forma as variáveis econômicas da taxa de câmbio, da taxa de juros, e da inflação, influenciaram nas variações dos custos proporcionais, no período de 2003 a 2015. Trata-se de uma pesquisa descritiva e quantitativa, realizada através de uma pesquisa documental. A coleta de dados das variáveis econômicas foi retirada no site do Banco Central do Brasil (BACEN) e no site do Instituto Brasileiro de Geografia e Estatística (IBGE). Os custos proporcionais foram calculados a partir de dados das demonstrações anuais, de cada indústria alimentícia, publicadas pela BOVESPA. A partir desta porcentagem, observou-se o quanto as variáveis econômicas mencionadas, influenciaram no comportamento dos custos proporcionais, utilizando-se do método estatístico da regressão linear múltipla, dentro de todo o perío do estudado. A partir dos resultados foi observado que to das as empresas da amostra são influenciadas substancialmente pelas variáveis econômicas em seus custos proporcionais. Isso indica que em todas as indústrias as variáveis econômicas foram influentes na variação dos custos proporcionais. Excetua-se deste conjunto somente a BRF S.A, que teve seu resultado considerado como moderado, o que significa que seu custo proporcional foi menos influenciado pelas variações econômicas.
\end{abstract}

Palavras chave: Custos proporcionais. Indústria. Variáveis econômicas.

\section{The variation of costs in food industries listed on BOVESPA}

\begin{abstract}
The purpose of this study was to demonstrate the variation of costs in food industries listed on the São Paulo Stock Exchange (BOVESPA), and how the economic variables of the exchange rate, interest rate, and inflation influenced the proportional costs, from 2003 to 2015. This is a descriptive and quantitative research, conducted through documentary research. Data collection of economic variables was made on the website of the Brazilian Central Bank (BACEN) and on the website of the Brazilian Institute of Geography and Statistics (IBGE). The proportional costs were calculated based on data from the annual statements of each food industry published by BOVESPA. From this percentage, we observed how much the economic variables mentioned, influenced in the behavior of the proportional costs, by using the statistical method of multiple linear regression, throughout the studied period. Results showed that all the companies of the sample are substantially influenced by the economic variables in their proportional costs. This indicates that in all industries the economic variables were influential in the variation of proportional costs. Only BRF S.A., which had its results considered as moderate, is not included in this group, meaning that its proportional cost was less influenced by economic variations.
\end{abstract}

Keywords: Proportional costs. Industry. Economic variables. 


\section{INTRODUÇÃO}

As organizações inseridas em um ambiente econômico globalizado têm se preocupado com os fatores que contribuem para otimizar a gestão, no sentido de competirem no mercado com um nível de qualidade imprescindível a sua continuidade operacional. A economia de um país constitui uma das principais ciências sociais que analisa o mercado em um contexto organizacional, tanto pelo no âmbito interno, relacionado à microeconomia, quanto pelo externo, direcionado para a macroeconomia.

Em meio à alta competitividade e a fatores ligados à economia, as empresas buscam inovações para ampliar o seu quadro econômico e, por sua vez, a sua capacidade de produção. Isso faz com que elas busquem um enfoque cada vez mais gerencial, utilizando-se da contabilidade de custos e gerencial, que passaram a ocupar um espaço relevante nas empresas brasileiras, como um importante instrumento para a administração de seus negócios. Martins (2010), afirma que devido ao aumento de competitividade que ocorre na maio ria dos mercados, como nos industriais, os custos tornam-se altamente relevantes para a tomada de decisões. "O conhecimento dos custos é vital para saber se, dado o preço, o produto é rentável; ou, se não rentável, se é possível reduzi-los (os

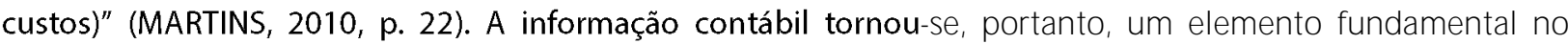
processo decisório das organizações, uma vez que corresponde a uma relevante ferramenta de análise e avaliação das mutações patrimoniais, resultado da escrituração contábil, o que inclui as etapas de coleta, tratamento e adequado registro dos fatos contábeis.

Dentro de um processo produtivo em uma organização, os custos de produção, podem variar de um período para o outro. As variações podem estar relacionadas com os fatores internos de produção bem como fatores externos decorrentes do mercado em que elas atuam.

Segundo dados do Instituto Brasileiro de Geografia e Estatística (IBGE), apresentados por Soares (2015), 0 PIB, Produto Interno Bruto, que representa a soma dos bens e serviços produzidos no país, ficou estagnado em 2014 , no Brasil, com alta de $0,1 \%$, sendo o pior resultado desde a retração de $0,2 \%$ registrada em 2009 , em meio à crise global. Ainda segundo o Jornal, a indústria foi o setor produtivo mais afetado, com queda de 1,2\% em 2014.

Entre os fatores que envolvem uma retração da atividade econômica estão: os juros mais altos, inflação pressionada e crédito mais escasso. 0 governo com objetivo de remunerar os títulos da dívida pública e controlar a inflação, eleva as taxas de juros, como ocorreu um aumento na taxa básica de juros de $13,75 \%$ para 14,25\% no ano de 2015 (BACEN, 2016b). Um aumento na taxa de juros afetará o investimento e o consumo negativamente e, assim, interferirá no crescimento da economia, uma vez que a taxa de juros desempenha um papel-chave na tomada de decisões econômicas, pois ela interfere nos preços e nos custos de todos os setores da economia (MENDONÇA, 2007; OMAR, 2008). Outro fator que pode variar os preços dos custos dos produtos é a taxa de câmbio, que tem como referência a moeda americana, o dólar, responsável pelas importações (SERRANO, 2004).

Desse modo, torna-se importante realizar um estudo, que se constitui em verificar como o comportamento dos fatores econômicos da taxa de câmbio, taxa de juros e da inflação, influenciam na variação dos custos proporcionais. Diante do exposto, este estudo buscou responder a seguinte questão: qual a influência da taxa de câmbio, da taxa de juros e da inflação nos custos proporcionais das indústrias alimentícias, no período de 2003 a 2015?

Baseando-se em tal questionamento, o objetivo desta pesquisa foi verificar, de acordo com o método estatístico da regressão linear múltipla, qual a influência da taxa de câmbio, da taxa de juros e da inflação, nos custos proporcionais das indústrias alimentícias, listadas na Bovespa, que tem como atividade principal a produção de carnes e derivados, no período de 2003 a 2015 (BOVESPA, 2016). Os objetivos específicos são: i. verificar a partir das demonstrações do resultado do exercício, qual percentual (custo proporcional) dos custos dos produtos vendidos com relação à receita líquida das indústrias alimentícias listadas na Bovespa; ii. comparar a variação dos custos dos produtos vendidos às variações da taxa de câmbio, da taxa de juros e da inflação no período de 2003 a 2015; e iii. identificar quanto as variáveis econômicas influenciaram no comportamento dos custos proporcionais.

No que se refere à organização, ressalta-se que além da introdução, o trabalho está estruturado em mais três seções. Na seção 2 apresentam-se os principais conceitos que deram suporte à pesquisa, o referencial teórico. $\mathrm{Na}$ seção 3 descrevem-se os caminhos trilhados para seu desenvolvimento, a metodologia. Na seção 4 apresentam-se os resultados encontrados e as análises efetuadas. E, por fim, na seção 5, apresentam-se as considerações finais. 


\section{REFERENCIAL TEÓRICO}

Este capítulo é composto pela revisão de literatura que sustenta a pesquisa e contempla os seguintes temas: Contabilidade de Custos; Taxa de Juros; Inflação; e Taxa de Câmbio.

\subsection{Contabilidade de Custos}

A contabilidade de custos surgiu na Revolução Industrial, que, com o crescente aumento de inúmeras indústrias, verificou-se a necessidade de calcular o custo dos produtos que eram fabricados bem como a apuração do real custo de estoques. Anterior a este cenário, existiam praticamente empresas comerciais que utilizavam basicamente a contabilidade financeira e não havia, portanto, a dificuldade da apropriação dos custos aos produtos (BORNIA, 2002; MARTINS, 2010). 0 enfoque específico nas informações sobre custos, extraídas da contabilidade financeira e comercial, permitem a construção de um processo mais simples e de fácil entendimento para a tomada de decisões (BRUNI, 2006).

Com o advento das indústrias, tornou-se mais complexa a função do Contador que, para levantamento do balanço e apuração do resultado, não dispunha agora tão facilmente dos dados para poder atribuir valor aos estoques; seu valor de "Compras" na empresa comercial estava agora substituído por uma série de valores pagos pelos fatores de produção utilizados (MARTINS, 2010, p. 20).

J ustamente por essa consequente proliferação de diversas indústrias, foram surgindo ao longo do tempo diversas publicações e técnicas, e isso se dá também pela decorrência do crescimento das empresas e de suas atividades operacionais, que dinamizaram a contabilidade com inúmeros avanços, especialmente, no que diz respeito ao desenvolvimento de sistemas de custos que sirvam de instrumento de suporte nas decisões (BEUREN, 1993). Desse modo, segundo Crepaldi (2010, p. 2), a "Contabilidade de Custos passou a ser uma técnica utilizada para identificar, mensurar e informar os custos dos produtos e/ou serviços, com a função de gerar informações precisas e rápidas para a administração, para tomada de decisões".

Segundo Crepaldi (2010) quando uma entidade tem um sistema de custos que funciona de forma eficiente é possível conhecer a lucratividade de cada produto, reduzir custos, decidir so bre a fabricação ou compra terceirizada de determinados produtos, determinar o preço que os produtos poderão ser vendidos dentro do mercado em que se encontra, avaliar o desempenho da empresa, entre outros benefícios. Com isso, para que os gestores das entidades possam tomar decisões que os levem rumo ao alcance dos lucros e de uma boa colocação no mercado, a contabilidade de custos é imprescindível, de grande importância, pois é através dela que serão fornecidas informações essenciais para as decisões.

Silva Junior et al $(2000$, p. 217) afirmam que "é imprescindível que sejam apresentadas informações que, extraídas do sistema de informações contábeis, representem uma base sólida para o planejamento da organização". Essas informações devem ser fidedignas e tempestivas para que os efeitos das decisões tomadas possam acarretar em um resultado mais próximo do que se espera ser alcançado.

As atividades de controle e o gerenciamento dos custos tornaram-se primordiais para a manutenção e o crescimento da empresa. Na maioria dos segmentos de mercado, não é possível aumentar o preço dos produtos vendidos, em virtude da crescente concorrência e retração dos mercados consumidores (OLIVEIRA; PEREZ JUNIOR; 2000, p. 20).

O controle efetivo das atividades produtivas é condição indispensável para que qualquer empresa possa competir em igualdade de condições com seus concorrentes. Os sistemas de contabilidade de custos atuam, então, como um alicerce gerencial para o controle e para as tomadas de decisões (BORNIA, 2002). 


\subsection{Taxa de Juros}

Segundo Gremaud, Vasconcellos e Toneto Júnior (2014), a taxa de juros é uma das variáveis mais acompanhadas na economia, pois seu comportamento afeta as decisões de investimento, além do fluxo de recursos externos para a economia, o valor da taxa de câmbio, e com isso a competitividade dos produtos do país. Ainda segundo os mesmos autores, a taxa de juros pode ser assim definida como:

o que se ganha pela aplicação de recursos durante determinado período de tempo, ou, alternativamente, aquilo que se paga pela obtenção de recursos de terceiros (tomada de empréstimo) durante determinado período de tempo (GREMAUD; VASCONCELLOS; TONETO JÚNIOR, 2014, p. 222).

Omar (2008) complementa que, a taxa de juros pode ser definida como o preço do uso do dinheiro para um determinado período de tempo. Porém, enquanto a taxa de juros for um preço, seu impacto na economia não é limitado para o seu próprio mercado. Portando, há estreitas relações entre a taxa de juros e as variáveis econômicas-chave, tais como a inflação, o desemprego, a taxa de câmbio, os fluxos de capital, a estrutura da balança de pagamentos e o nível da dívida externa e interna.

A taxa de juros também é influenciadora nas decisões de vários agentes e atores da economia, como empresas, consumidores, governo etc. Quando as taxas de juros estão baixas, os consumidores detêm maior poder de compra, e acabam por adquirir mais bens. Quando ocorre o inverso, as pessoas tendem a reduzir 0 consumo e passam a poupar mais (LANZANA, 2002). No âmbito empresarial, as taxas de juros interferem muito no que diz respeito aos investimentos, pois quando os juros estão altos, as empresas preferem trabalhar com menos estoques e menos capital de giro, uma vez que o custo de manutenção desses ativos poderá ser extremamente oneroso no futuro.

O nível da taxa de juros também vai afetar as decisões de investimentos em bens de capita, pois se as taxas estiverem elevadas, isso inviabilizará muitos projetos de investimentos, e os empresários optarão por aplicar recursos no mercado financeiro, que acaba por ser uma opção mais atrativa (VASCONCELLOS; GARCIA, 2006). A drástica elevação nos juros também pode acarretar uma considerável desaceleração no crescimento do crédito, bem como um forte aumento da taxa de inadimplência (PAULA, 1998).

Para o lado governamental, a taxa de juros também tem impacto direto, já que quando a taxa de juros aumenta, a dívida interna também aumenta, consequentemente, pressionando o déficit público (LANZANA, 2002). Mas vale lembrar que tal atitude se deve a preocupação do governo com o aumento excessivo do consumo, e que tal situação pode desestabilizar a economia com o retorno da inflação (OMAR, 2008).

Historicamente, as autoridad es brasileiras usaram taxas de juros altas como um instrumento para alcançar dois principais objetivos: combater a inflação e servir como instrumento para atrair capital externo com a finalidade de cobrir o déficit da conta corrente na balança de pagamentos e aumentar as reservas internacionais. A mesma política, porém, produziu efeitos negativos sobre o investimento, aumentando não apenas o déficit do governo e a dívida pública, como também a vulnerabilidade externa da economia brasileira (OMAR, 2008).

A taxa básica oficial de juros na economia brasileira é a taxa SELIC (Sistema Especial de Liquidação e Custódia), que de acordo com o BACEN (2016c), é a taxa média ajustada dos financiamentos diários apurados no Sistema Especial de Liquidação e de Custódia (SELIC) para títulos federais, ou seja, é a taxa utilizada para negociação de títulos públicos. É o instrumento utilizad o pelo BACEN para manter a inflação sob controle ou para estimular a economia. A taxa de juros é fixada nas reuniões feitas pelo Comitê de Política Monetária (COPOM), onde se estabelece a meta para a taxa SELIC (BACEN, 2016c).

\subsection{Inflação}

O fenômeno macroeconômico da inflação pode ser definido como o processo persistente de aumento do nível geral dos preços, o que resulta em perda do poder aquisitivo da moeda. A inflação é considerada um fenômeno generalizado, pois os aumentos dos preços não ocorrem apenas sobre um pequeno conjunto de preços ou so bre um setor específico da economia (PASSOS; NOGAMI, 2010). A inflação assim é definida como um aumento generalizado e contínuo dos preços que significa dizer a perda do poder aquisitivo da moeda, ou seja, 
uma mesma unidade monetária pode adquirir menos bens e serviços (GREMAUD; VASCONCELLOS; TONETO JUNIOR, 2014).

A economia brasileira já passou por diversas experiências inflacionárias ao longo das últimas décadas, com início no Governo Castelo Branco (1964-1967) até o Plano Real (1994), onde alguns programas de estabilização como o Cruzado I, Cruzado II, Bresser, Verão, Collor I, Collor II foram instaurados, porém não obtiveram sucesso; foi ainda um período onde o país esteve à beira da hiperinflação no final do Governo Sarney no ano de 1990 (LANZANA, 2002).

É muito importante o esforço teórico e empírico para descrever os fatos reais e alcançar a estabilidade dos preços. Além de aumentar o horizonte de previsibilidade dos agentes econômicos, a preservação do nível geral de preços favorece a preservação do poder de compra dos salários reduzindo a incerteza e favorecendo 0 investimento. Consequentemente, contribui para melhor distribuição de renda, sustentando a demanda agregada e assegurando maior crescimento ao longo do tempo (CAETANO; CORRÊA, 2006).

Várias são as consequências de taxas de inflação elevada, "o primeiro efeito é provocar distorções na alocação de recursos da economia, uma vez que os preços relativos deixam de ser sinalizadores da escassez e dos custos relativos de produção" (GREMAUD; VASCONCELLOS; TONETO JUNIOR, 2014, p. 99).

Portanto, quando a inflação é elevada e está em aceleração, o papel dos preços relativos de determinado produto que antes se tinha como referência, deixa de existir. 0 que gera um efeito negativo nos investimentos, uma vez que os agentes terão dificuldades para prever o retorno dos investimentos, dada a instabilidade dos preços no futuro (CAETANO; CORRÊA, 2006; GREMAUD; VASCONCELLOS; TONETO JUNIOR, 2014).

Outras ocorrências relevantes para a economia, ligadas à elevação das taxas de inflação, convergem principalmente nos assuntos que dizem respeito à distribuição de renda, balanço de pagamentos, investimentos empresariais e finanças públicas. Quanto à distribuição de renda pode-se perceber uma distorção séria derivada da inflação, pois as classes que dependem de salários fixos perdem o poder de compra, já que os preços dos bens e serviços sobem ao longo do tempo, e os salários dessas classes só aumentam de acordo com prazos legais de reajuste. Assim, os trabalhadores de baixa renda são os mais afetados, pois seus salários são utilizados para manter sua subsistência, não tendo então condições de se proteger desse processo inflacionário. Assim argumenta Vasconcellos (2011).

No que se refere ao balanço de pagamentos, quando a elevação dos preços nacionais é maior que a elevação dos preços internacionais, o produto nacional fica mais caro e provoca, consequentemente, estímulo às importações.

elevadas taxas de inflação, em níveis superiores ao aumento dos preços internacionais, encarecem o produto nacional relativamente ao produzido externamente, diminuindo a competitividade de nossos produtos. Assim devem provocar um estímulo às importações e um desestímulo às exportações, diminuindo o saldo da balança comercial. Se o saldo comercial tornar-se deficitário e o país já apresentar um saldo em conta corrente negativo, aumenta sua dependência em relação aos empréstimos externos (VASCONCELLOS; GARCIA, 2006, p. 187).

No que diz respeito às expectativas sobre o futuro, principalmente no setor empresarial, cria-se uma incerteza nos investimentos. Segundo Vasconcellos (2011), o empresário fica em um compasso de espera enquanto a situação perdurar, e dificilmente tomará iniciativas próprias para aumentar seus investimentos com o objetivo de expandir sua capacidade produtiva. Assim, a própria capacidade de produção futura e, consequentemente, o nível de emprego são afetados negativamente pelo processo inflacionário.

Já sobre as finanças públicas, a inflação tende a corroer o salário dos trabalhadores, que passam a consumir menos, e consequentemente as empresas passam a vender menos e o governo a arrecadar menos tributos. Desse modo, a inflação tende a corroer o valor da arrecadação fiscal do governo, pela defasagem entre o fato gerador e o recolhimento de impostos (GREMAUD; VASCONCELLOS; TONETO JUNIOR, 2014).

Existem, no Brasil, vários indicadores de inflação. Cada um mede a inflação em determinada área da economia, sendo que alguns são mais voltados para reajustes salariais, outros para reajustes de contratos, outros utilizados para corrigir balanços de companhias abertas etc. Lanzana (2002) destaca os principais indicadores de preços na economia brasileira os seguintes: Índice Nacional de Preços ao Consumidor (INPC), Índice de Preços ao Consumidor (IPC-Fipe), Índice de Custo de Vida (ICV-Dieese), Índice Geral de Preços (IGP), Índice Geral de Preços no Mercado (IGPM), Índice de Preços por Atacado (IPA) e o Índice de Preços ao Consumidor Ampliado (IPCA), que representa o índice oficial de inflação no país. 
Ressalta-se que todos os indicadores de inflação acima citados, com exceção do Índice Geral de Preços no Mercado (IGPM), coletam dados do primeiro ao último dia do mês de referência. Com relação à abrangência destes índices, a maioria possui uma área de cobertura com diversas regiões, com exceção do Índice de Custo de Vida (ICV-Dieese) que se refere ao município de São Paulo (LANZANA, 2002).

\subsection{Taxa de Câmbio}

Para que os países possam estabelecer relações econômicas entre si, na compra e venda de produtos, é necessária a existência da taxa de câmbio, que nada mais é, que uma medida de conversão de uma moeda em outra, pois cada país adota uma moeda específica, e não aceita pagar ou receber em moeda diferente daquela adotada em seu país. Segundo Gremaud, Vasconcellos e Toneto Junior (2014, p. 265), "taxa de câmbio é o valor que uma moeda nacional possui em termos de outra moeda nacional; é a taxa pela qual duas moedas de países diferentes podem ser trocadas (cambiadas)". É através desta taxa de câmbio que os países podem realizar transações uns com os outros como, por exemplo, na exportação e importação de produtos.

Quando se fala em taxas de câmbio, podem-se destacar dois tipos, as taxas de câmbio fixas e as taxas de câmbio flutuantes, que diferem-se pelo fato de o governo interferir ou não na sua determinação. As taxas de câmbio fixas fazem parte de um regime nos quais o valor da taxa de câmbio não se altera, somente mudam as quantidades da demanda e oferta destas taxas de câmbio. Nesse regime o governo interfere diretamente, sendo obrigado a disponibilizar suas reservas cambiais quando necessário (GREMAUD; VASCONCELLOS; TONETO JUNIOR, 2014).

Na verdade, nesse regime, o governo, geralmente por meio de seu Banco Central, intervém, de modo a equilibrar a oferta e a demanda de divisas no nível da taxa de câmbio estabelecida. Quando, no mercado, em relação a dada taxa de câmbio, há excesso de oferta de divisas, o governo entra no mercado adquirindo divisas pela taxa de câmbio fixada. Se tiver o inverso, excesso de demanda por divisas, o governo vende, a essa taxa, divisas que possuiu em reservas (GREMAUD; VASCONCELLOS; TONETO JUNIOR, 2014, p. 269).

Segundo Lanzana (2002) o regime de taxa de câmbio fixo normalmente é adotado por países que têm problemas inflacionários, onde estes veem na taxa de câmbio fixo um método para combater a inflação, porque desse modo o preço dos produtos importados para de subir.

Vasconcellos e Garcia (2006) destacam como desvantagem deste regime o fato de que, como é obrigatória a disponibilização das reservas cambiais, estas ficam mais vulneráveis a elevações na demanda por moeda estrangeira que pode ocorrer por pagamentos elevados de dívida externa e até mesmo por ataques especulativos. E, quando esses ataques ocorrem o país tem que elevar as taxas de juros para evitar saídas de reservas.

Já as taxas de câmbio flutuantes fazem parte de um regime onde, ao contrário das taxas de câmbio fixas, o governo não é obrigado a disponibilizar suas reservas cambiais. Nesse regime a taxa de câmbio é flexível, e é determinada pelo mercado, pela oferta e demanda de moeda estrangeira (VASCONCELLOS; GARCIA, 2006). Segundo Gremaud, Vasconcellos e Toneto Junior $(2014$, p. 270) "o preço da moeda nacional em termos de moeda estrangeira oscila livremente, para garantir o equilíbrio entre a oferta e a demanda de divisas".

Pode-se destacar como vantagem no regime de taxa de câmbio flutuante o fato de as reservas cambiais ficarem mais protegidas, já que o Banco Central não precisa mexer nas mesmas. Por outro lado, existe a possibilidade de o Banco Central intervir indiretamente na taxa de câmbio, na compra ou venda de divisas no mercado, para que esta taxa fique de acordo com que ache que esteja adequado para a política econômica do país (VASCONCELLOS; GARCIA, 2006).

Na verdade, mesmo dentro do regime de câmbio flutuante o Banco Central interfere indiretamente na determinação da taxa de câmbio, por meio de compra e venda de divisas no mercado, mantendo-a dentro de níveis que julga adequados, dependendo dos objetivos gerais de política econômica. Esse fato é chamado de flutuação suja, ou dirty floating, e é o regime cambial adotado atualmente pela maioria dos países (VASCONCELLOS; GARCIA, 2006, p. 170).

No Brasil, a moeda estrangeira mais negociada é o dólar dos Estados Unidos, fazendo com que a cotação comumente utilizada seja a dessa moeda. A taxa de câmbio reflete, assim, o custo de uma moeda em relação à 
outra. As cotações apresentam taxas para a compra e para a venda da moeda, as quais são referenciadas do ponto de vista do agente autorizado a operar no mercado de câmbio pelo Banco Central. 0 regime cambial adotado no Brasil é o regime de câmbio flutuante, onde o Banco Central não fixa nenhuma taxa de câmbio. As taxas de câmbio são livremente pactuadas entre as partes contratantes, ou seja, entre o comprador ou vendedor da moeda estrangeira e o agente autorizado pelo Banco Central a operar no mercado de câmbio (BACEN, 2016a). Dessa maneira, se em determinada data o dólar estiver cotado a $\mathrm{R} \$ 3,60$, e se um produto a ser importado custar US\$ 100,00 , o preço em reais deste produto será de $\mathrm{R} \$ 360,00$.

\section{METODOLOGIA}

O presente trabalho foi efetuado mediante uma pesquisa descritiva quanto aos objetivos. Segundo Gil (2002), uma das principais características da pesquisa descritiva está na utilização de técnicas padronizadas de coleta de dados, com o objetivo de descrever traços de determinada população ou fenômeno ou 0 estabelecimento de relações entre as variáveis. A pesquisa descritiva, é aquela que observa, registra, analisa e correlaciona fatos ou fenômenos (variáveis) sem manipulá-los. Procura descobrir, com a maior precisão possível, a frequência com que um fenômeno ocorre, sua relação e conexão com outros, sua natureza e suas características (CERVO; BERVIAN; SILVA, 2007).

Quanto aos objetivos a pesquisa é configurada como documental. Segundo Vergara (2004), a pesquisa documental é realizada em documentos conservados no interior de órgãos públicos e privados de qualquer natureza, ou com pessoas, que podem ser realizadas através de registros, balancetes, comunicações informais, entre outros. São empregadas fontes primárias, assim considerados os materiais compilados pelo próprio autor do trabalho, que ainda não foram objeto de análise, ou que ainda podem ser reelaborados de acordo com os propósitos da pesquisa (THEÓPHILO; MARTINS, 2016).

Com relação à abordagem foi aplicada uma pesquisa quantitativa. Segundo Michel (2005) a pesquisa quantitativa é um método de pesquisa social que utiliza a quantificação nas modalidades de coleta de informações e no seu tratamento, mediante técnicas estatísticas, tais como: percentual, média, desvio-padrão, coeficiente de correlação, análise de regressão, entre outros. Richardson (1999) expõe que este método é frequentemente aplicado nos estudos descritivos, os quais procuram descobrir e classificar a relação entre variáveis, em que propõem investigar as características de um fenômeno como tal.

O objeto da presente pesquisa foram empresas do ramo alimentício, do setor de carnes e derivados, listadas na BOVESPA. As indústrias alimentícias estudadas no presente trabalho foram: BRF S.A; Excelsior Alimentos S.A; J BS S.A; Marfrig Global Foods S.A; Minerva S.A; e, Minupar Participações S.A.

Para elaboração da pesquisa foi necessária à coleta de dados das demonstrações financeiras das empresas e das variáveis inflação, juros e dólar. A partir das demonstrações, situadas no portal da BOVESPA, foram encontrad os os custos dos produtos vendidos das empresas, bem como as receitas líquidas anuais, dos exercícios de 2003 a 2015, para cálculo dos custos proporcionais, que é a relação do custo dos produtos vendidos com a receita líquida. O IPCA, indicador de inflação utilizado na pesquisa, foi retirado do site do IBGE - Instituto Brasileiro de Geografia e Estatística, em versão anual. A taxa de juros SELIC foi coletada no site do Banco Central do Brasil (2016b), onde os valores foram apresentados de acordo com reuniões do Copom, que ocorreram algumas vezes durante os anos. Para que se pudesse utilizar essa variável em versão anual, foi feita uma média com todos os valores apresentados nestas reuniões durante cada ano. E, a taxa de câmbio utilizada foi o dólar americano, sendo que esta variável foi extraída também no site do Banco Central do Brasil (2016a). Assim como no caso da SELIC, com o dólar foi realizada uma média com os valores apresentados durante cada ano - valores estes apresentados com cotação diária - para que se pudesse chegar em valores anuais.

Posterior à coleta dos dados, foi calculado o custo proporcional de cada empresa, bem como aplicado, através no programa Microsoft Excel, o método estatístico da regressão linear múltipla. Segundo Oliveira et al (2014), regressão é "o estudo que busca ajustar uma equação a um conjunto de dados multivariados de forma que a relação entre as variáveis possa ser descrita matematicamente". Assim, regressão linear múltipla é um modelo de regressão capaz de explicar a relação de várias variáveis independentes - no caso a inflação, os juros e o dólar - com uma variável dependente - o custo proporcional, ao contrário da regressão linear simples, que leva em consideração apenas uma variável independente (MONTGOMERY; RUNGER, 2012). 
A partir da regressão linear múltipla, foi possível encontrar o " $R$-quadrado" ou " $R$ ", , denominado coeficiente de determinação, capaz de medir a proporção da variabilidade em que uma variável dependente custo proporcional - pode ser explicada pelas variáveis independentes - inflação, os juros e o dólar. 0 valor do coeficiente de determinação pode variar de 0 a 1 , sendo que quanto mais próximo de 1, mais acurado é o resultado obtido entre as variáveis (WALPOLE et al, 2010).

A parametrização dos resultados foi estabelecida de acordo com as medidas mencionadas por Hair et al (2014) e Chin (1998). De acordo com Hair et al (2014) os valores de 0,75, 0,50 e 0,25 são considerados respectivamente substanciais, moderados e fracos. Enquanto que para o autor Chin (1998) os valores 0,67, 0,33 e 0,19 são considerados, respectivamente, substancial, moderado e fraco.

\section{APRESENTAÇÃO DOS RESULTADOS}

Neste capítulo são apresentados e analisados os resultados do trabalho. Esta seção é dividida em três partes. Na primeira fez-se análises das variáveis econômicas; na segunda fez-se análises dos custos proporcionais; e por fim, na terceira, fez-se análises sobre os coeficientes de determinação encontrados.

\subsection{Análises das variáveis econômicas}

O Gráfico 1 demonstra a média anual da taxa de câmbio representada pelo dólar dos Estados Unidos da América, cotado em reais para a compra, estabelecido pelo BACEN. Para a realização da análise de sua variação, foi calculada a média anual do valor do dólar cotado em reais.

Durante estes 13 anos, percebeu-se que o dólar se apresentou com menor valor médio para compra no ano de 2011, com uma média anual de $\mathrm{R} \$ 1,67$. Porém, nos anos subsequentes, o valor do dólar aumentou, até chegar em 2015 com o dobro do valor de 2011, conforme demonstrado no Gráfico 1.

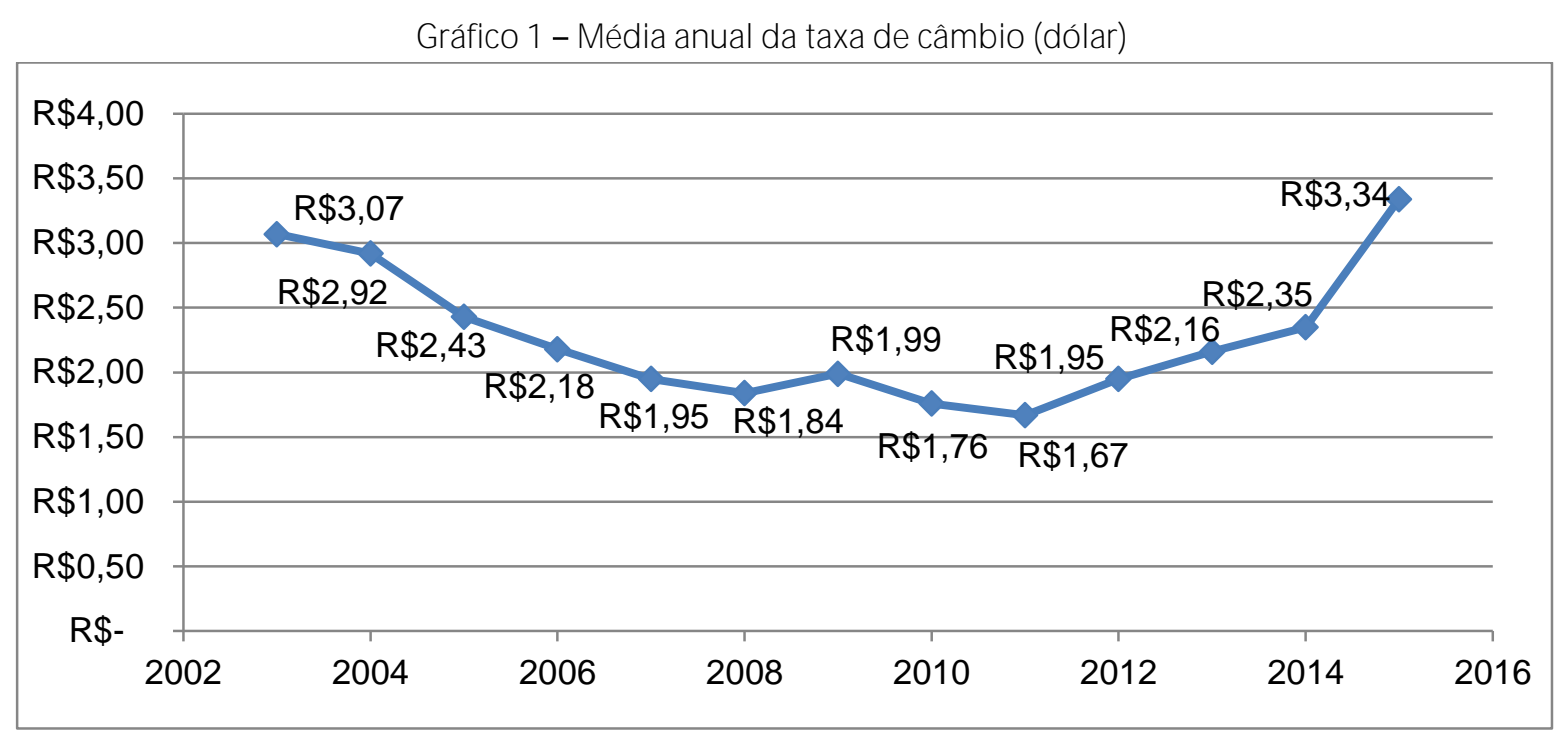

Fonte: Elaborado pelos autores (2016)

O Gráfico 2 apresenta a média anual da taxa de juros SELIC, onde observou-se que no ano de 2003 foi o ano em que a SELIC esteve com sua média mais elevada, e que em 2004 teve uma queda de aproximadamente $6 \%$. E em dez anos depois foi constatada a menor média anual da SELIC, sendo está de $8,15 \%$ o que corresponde a uma diferença de 14,9\% em comparação com o ano de maior elevação da taxa de juros, que foi 2003. 
Gráfico 2 - Média anual da taxa de juros (SELIC)

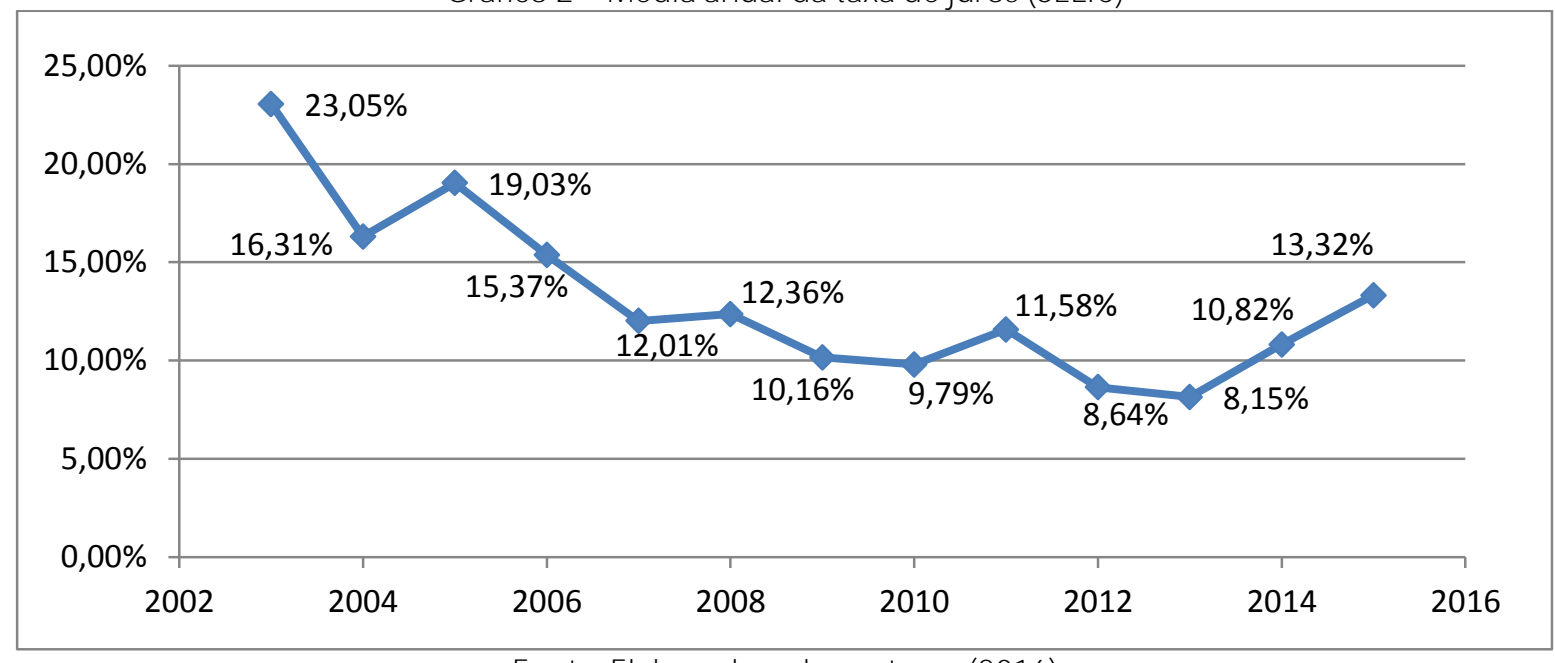

Fonte: Elaborado pelos autores (2016)

Já no Gráfico 3, demonstra a inflação acumulada anual, onde observou-se que em 2003 a inflação estava alta, com um percentual de 9,30\%, e que foi decrescendo nos anos subsequentes, até chegar em 2006 com um percentual de 3,14\%, sendo este o menor percentual em todo período analisado da inflação. Percebeu-se também que a maior elevação da inflação ocorreu em 2015, com percentual de 10,67\%, aproximadamente $4 \%$ a mais que a inflação do ano de 2014.

Gráfico 3 - Inflação acumulada anual (IPCA)

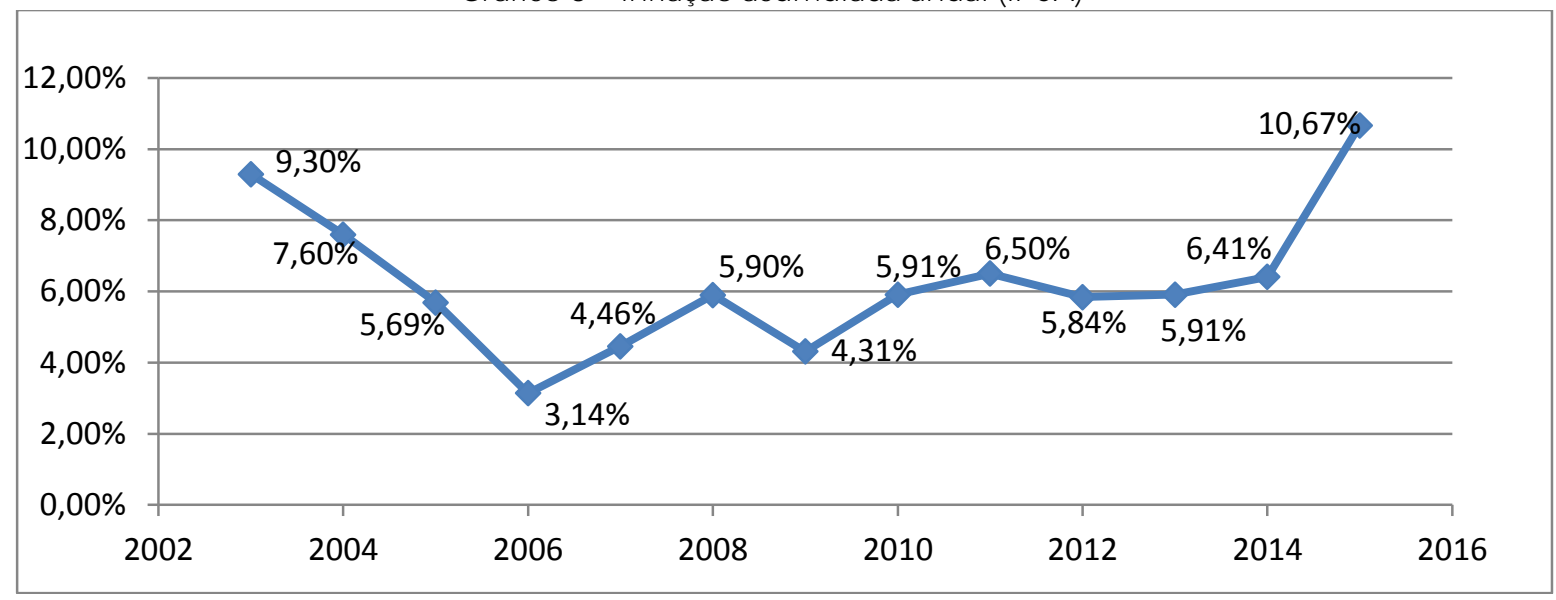

Fonte: Elaborado pelos autores (2016)

\subsection{Análises dos custos proporcionais}

Nos gráficos desta seção foram verificadas a partir da DRE de cada empresa, e divulgadas pela BOVESPA, qual foi o percentual que os custos dos produtos vendidos representam do total da receita líquida, dentro de cada exercício analisado, ou seja, o custo proporcional.

O Gráfico 4 apresenta os custos proporcionais da indústria alimentícia BRF S.A. Foi observado que em 2012 a proporção dos custos foi maior, o que representou 77,37\%. Nos anos seguintes esta proporção foi decrescendo, até chegar em 2015 com o menor percentual, o qual foi de $68,66 \%$, dentro da série analisada nesta empresa. 
Gráfico 4 - Custos proporcionais da indústria BRF S.A.

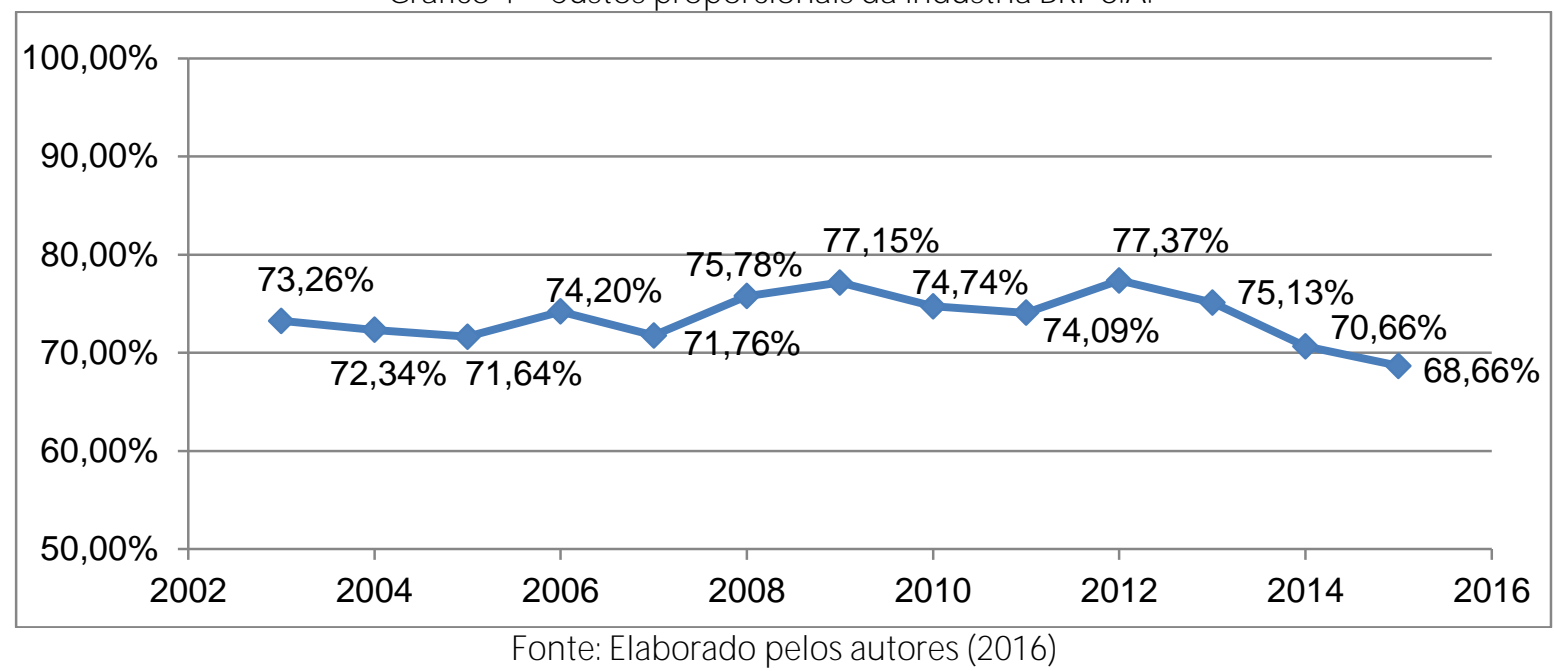

O Gráfico 5 apresenta os custos proporcionais da indústria alimentícia Excelsior S.A. Observa-se que no ano de 2010 os custos proporcionais foram de $80,96 \%$, com um aumento de mais de $7 \%$ em relação ao ano anterior, representando assim a maior proporção dentro diante da analise realizada nesta empresa. Notou-se também que no ano seguinte de 2011 a empresa conseguiu reduzir seus custos proporcionais em aproximadamente $12 \%$. No exercício de 2005 foi que a empresa, dentre os 13 anos analisados, obteve a menor porcentagem de custo proporcional, com o índice de 60,01\%.

Gráfico 5 - Custos proporcionais da indústria Excelsior S.A.

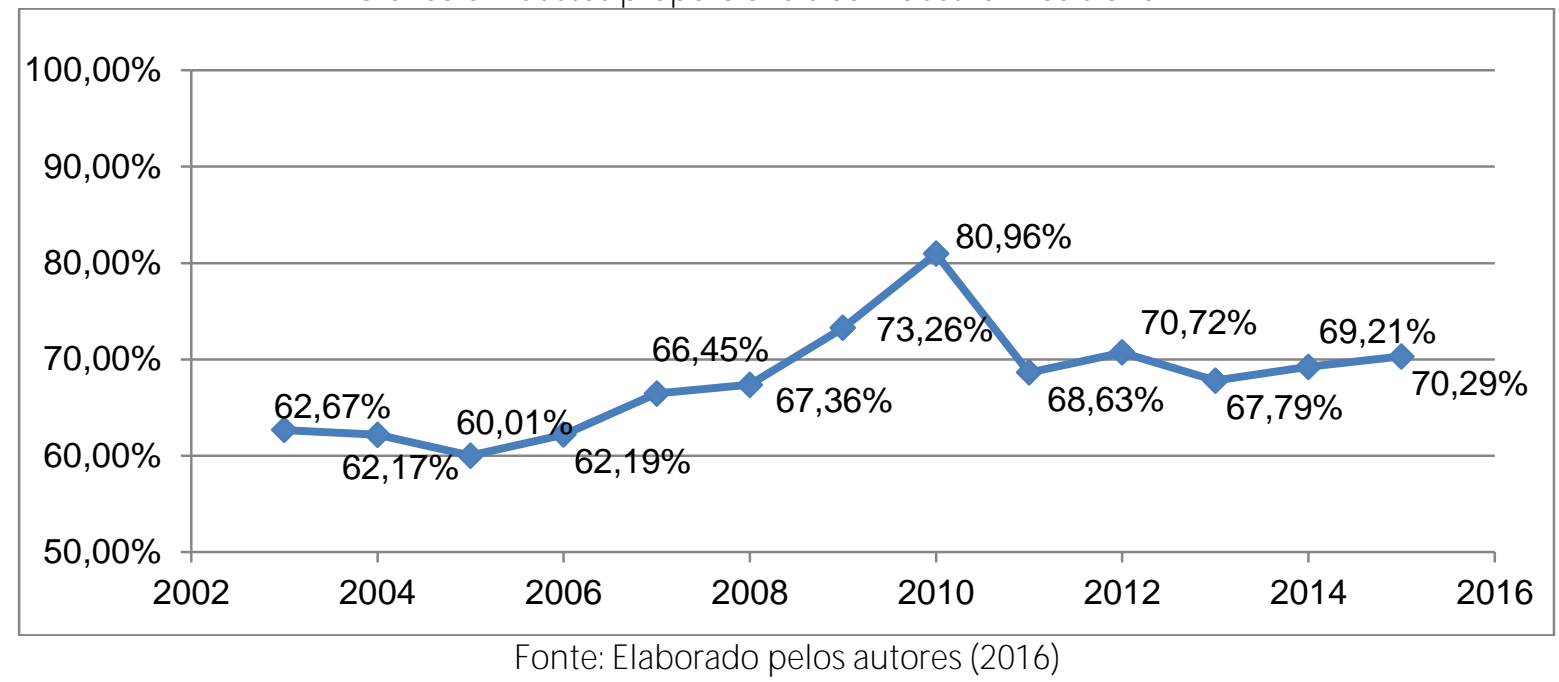

O Gráfico 6 apresenta os custos proporcionais da indústria alimentícia JBS S.A. Nesta empresa foram analisados 12 anos, de 2004 a 2015. No ano de 2003 não foi publicado a DRE pela BOVESPA. Percebeu-se com a análise desta empresa, que na maior parte dos anos analisados os custos representam mais de $80 \%$ da sua receita líquida. E que em 2006 representou a menor proporção, sendo esta de 75,52\%. Já em 2009, passados três anos, os custos tiveram um aumento de mais de $15 \%$, representado por $90,68 \%$, sendo este a maior proporção dos custos em relação à receita líquida. 
Gráfico 6 - Custos proporcionais da indústria JBS S.A)

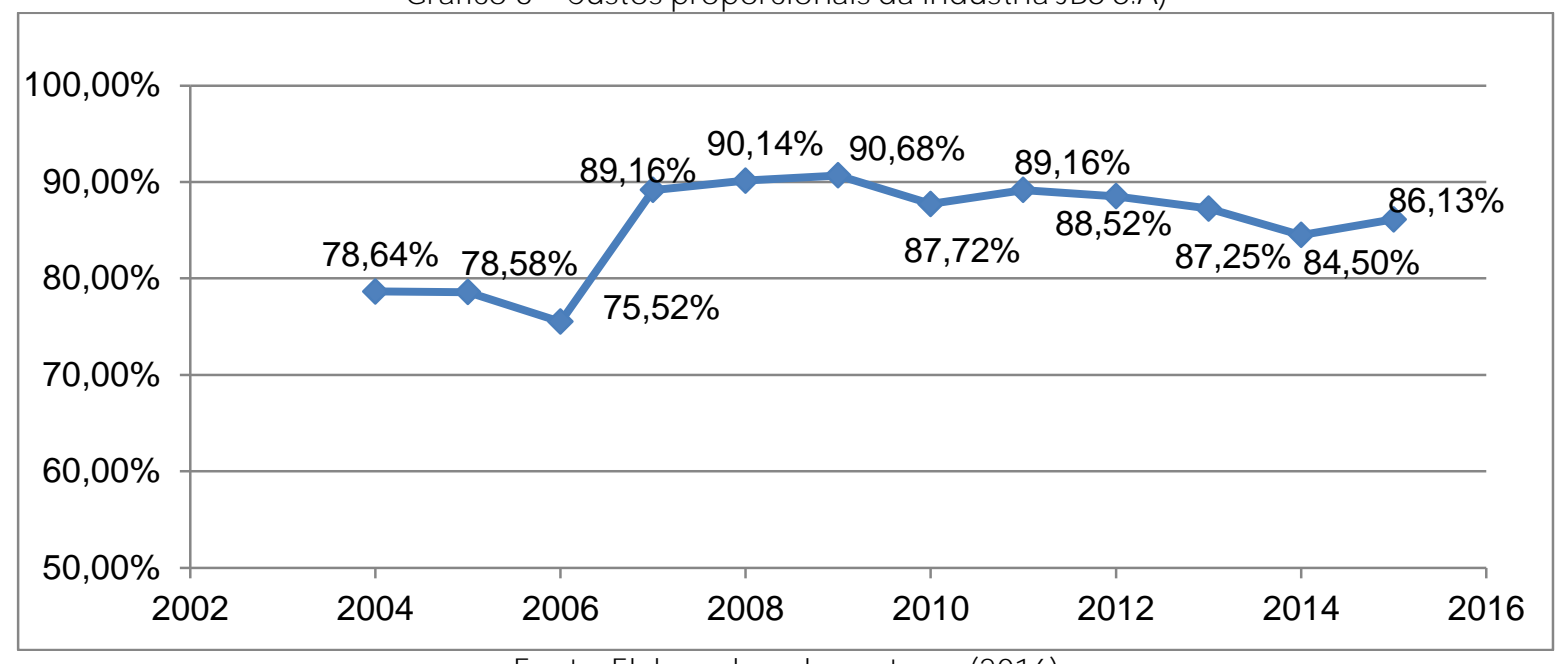

Fonte: Elaborado pelos autores (2016)

O Gráfico 7 apresenta os custos proporcionais da indústria alimentícia Marfrig Global Foods S.A. Nesta empresa, observou-se que a maioria dos custos proporcionais representou um índice maior que $80 \%$. Apenas em 2008 houve um valor mais baixo em relação aos anos estudados, de 78,61\%. Já o ano em que os custo proporcional foi mais elevado foi em 2015, representando 87,81\%, aproximadamente $10 \%$ a mais do que em 2008.

Gráfico 7 - Custos Proporcionais da indústria Marfrig Global Foods S.A.

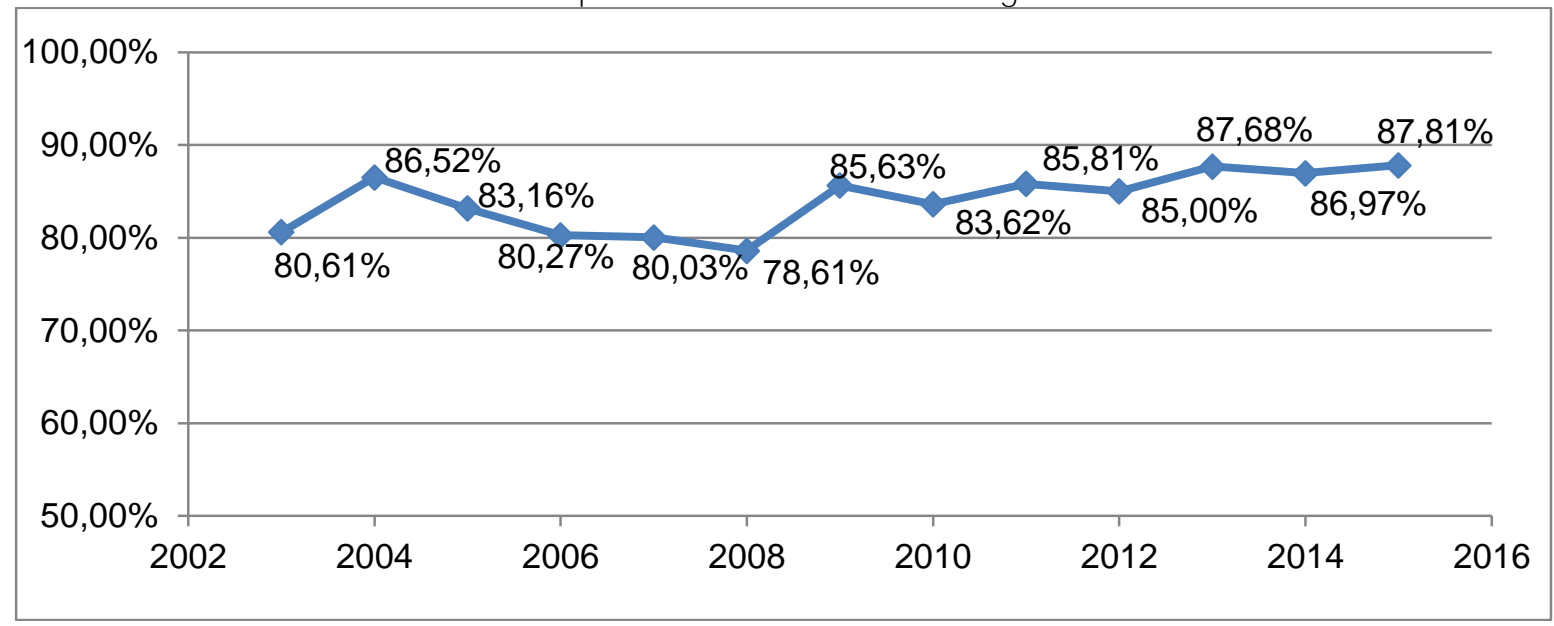

Fonte: Elaborado pelos autores (2016)

O Gráfico 8 apresenta os custos proporcionais da indústria alimentícia Minerva S.A. Assim como na empresa JBS S.A., na empresa Minerva S.A. também não foi analisado o ano de 2003, por não ter sido publicado a DRE deste ano pela BOVESPA. Percebeu-se que no primeiro ano analisado, que foi 0 ano de 2004, a proporção dos custos foi de 76,57\%, sendo esta a menor proporção dos custos em relação à sua receita líquida. Em 2011, foi 0 ano em que os custos tiveram mais representatividade, com um percentual de $84,90 \%$. 
Gráfico 8 - Custos proporcionais da indústria Minerva S.A

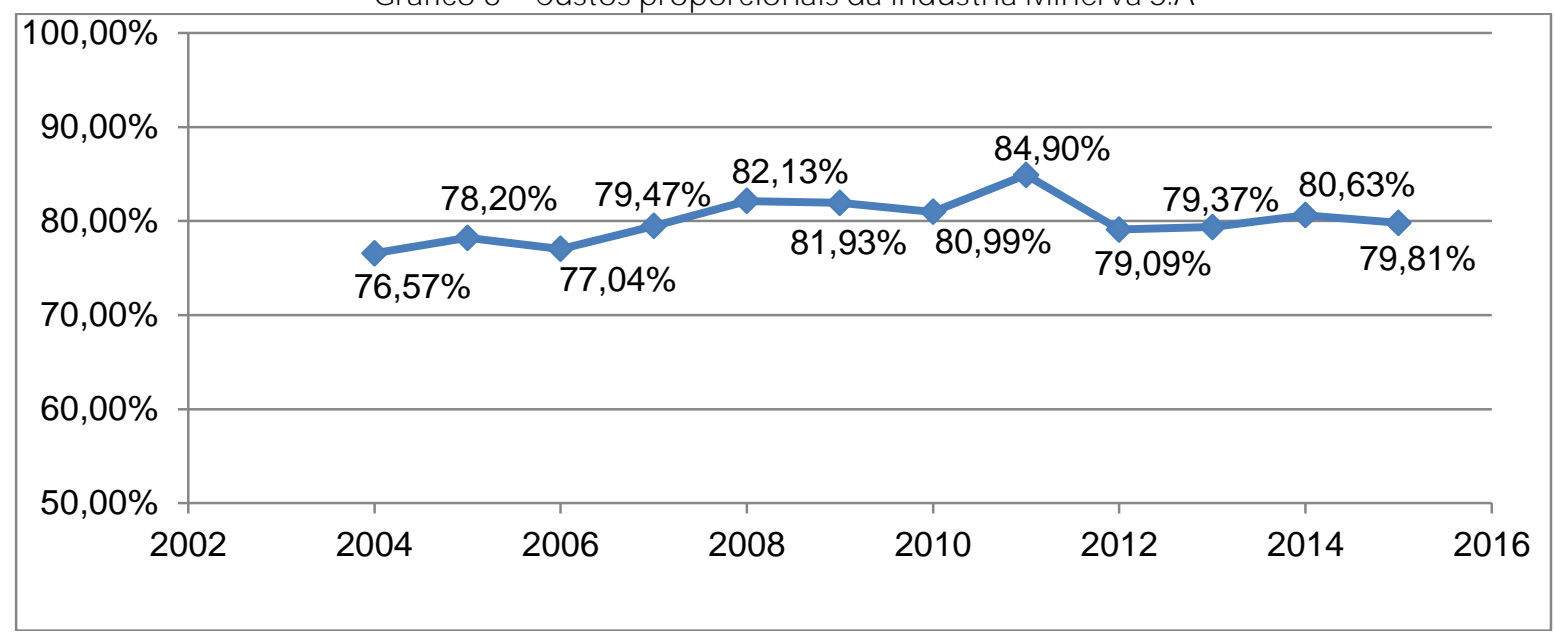

Fonte: Elaborado pelos autores (2016)

O Gráfico 9 apresenta os custos proporcionais da indústria alimentícia Minupar Participações S.A. Em 2003, o custo proporcional desta empresa, chegou a quase 90\%. Já em 2004, houve uma redução de aproximadamente $8 \%$. Entre anos de 2010 a 2012, foram os anos em que os custos chegaram a representar mais de $90 \%$ da receita líquida. Sendo em 2012 o mais elevado de todos, que chegou a representar exatamente $94,29 \%$. Nos anos de 2013, 2014 e 2015 esta proporção diminuiu, sendo que em 2015 o custo proporcional representou $77,45 \%$, o menor de todo o período analisado desta empresa.

Gráfico 9 - Custos Proporcionais da indústria Minupar Participações S.A

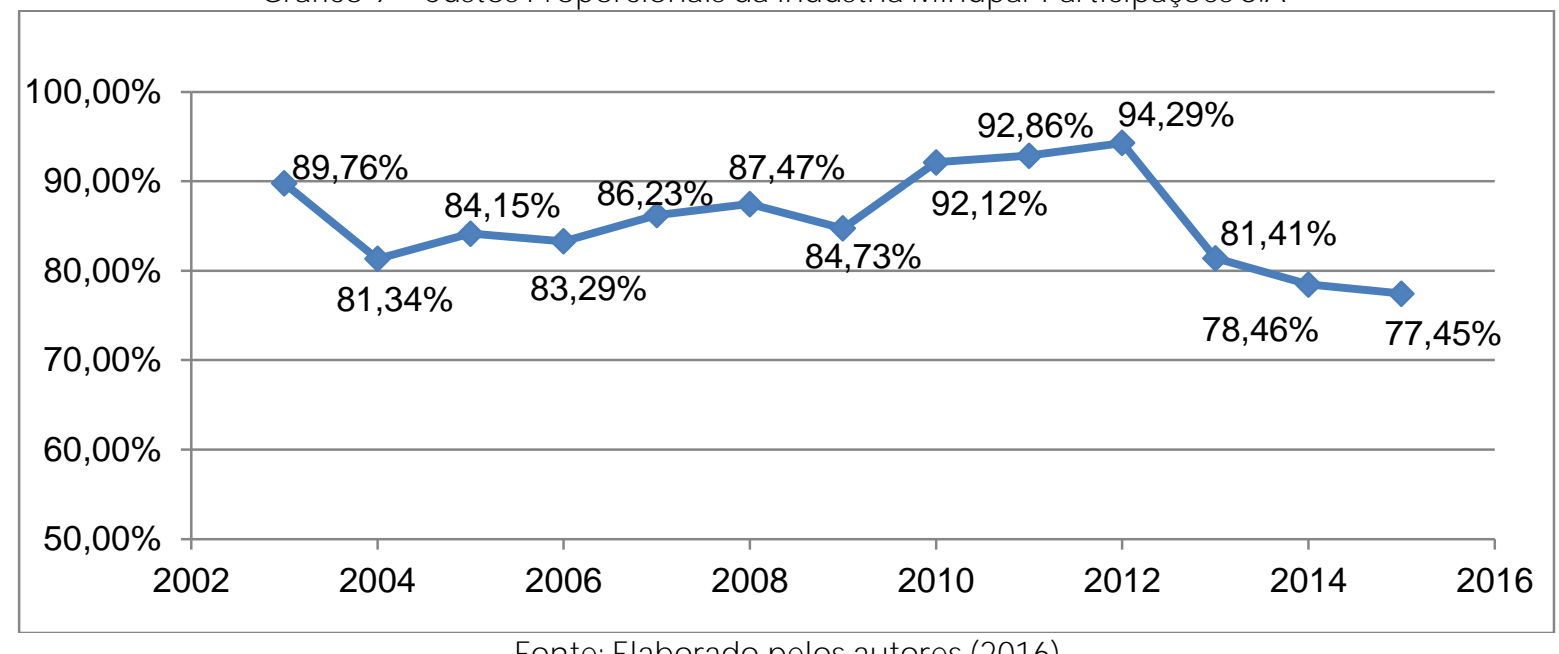

Fonte: Elaborado pelos autores (2016)

\subsection{Análises do coeficiente de determinação}

A regressão linear múltipla foi o método estatístico utilizado para explicar o comportamento da variação dos custos proporcionais das empresas do ramo alimentício, do setor de carnes e derivados, listadas na BOVESPA. Esta regressão analisou de forma simultânea os custos proporcionais com as três variáveis especificadas: inflação, juros e dólar.

Ao realizar a regressão múltipla, foi possível encontrar o "R-quadrado", que é o coeficiente de determinação capaz de medir a proporção da variabilidade em que uma variável dependente - neste caso os 
custos proporcionais - pode ser explicada pelas variáveis independentes - inflação, juros e dólar. 0 valor do coeficiente de determinação pode variar entre 0 a 1, sendo que quanto mais próximo de 1, mais forte é a relação entre as variáveis (WALPOLE et al, 2010).

Encontra-se, portanto, na Tabela 1, o valor do coeficiente de determinação encontrado de cada indústria analisada, no período de 2003 a 2015, com exceção das empresas J BS S.A. e Minerva S.A., que foram aplicados nos exercícios de 2004 a 2015.

Tabela 1 - Coeficiente de determinação das empresas analisadas

\begin{tabular}{l|c}
\hline \multicolumn{1}{c|}{ Empresas } & Coeficiente de Determinação (R-quadrado) \\
\hline JBS S.A. & 0,73 \\
Minerva S.A. & 0,67 \\
Minupar Participações S.A. & 0,66 \\
Excelsior S.A. & 0,61 \\
Marfrig Global Foods S.A. & 0,57 \\
BRF S.A. & 0,43 \\
\hline
\end{tabular}

Fonte: Elaborado pelos autores (2016)

Como demonstrado na Tabela 1, o R-quadrado da empresa BRF S.A. foi de 0,43, que conforme 0 entendimento de Hair et al (2014), obteve um resultado moderado. Isso significa que as variáveis econômicas analisadas, explicaram $43 \%$ da variação dos custos proporcionais em toda a série analisada.

As demais empresas obtiveram resultados do valor de R-quadrado entre 0,57 e 0,73 que conforme Hair et al (2014), são resultados substanciais, ou seja, representaram mais de $50 \%$ das variações ocorridas nos custos proporcionais.

Ao se analisar pelo parâmetro determinado por Chin (1998), os valores obtidos do R-quadrado de todas as empresas analisadas se classificaram como substanciais, uma vez que para este autor, valores de coeficiente de determinação acima de 0,34 são classificados como tal, isso indica que em todas as empresas as variáveis econômicas foram influentes na variação dos custos proporcionais.

Notou-se que a indústria JBS S.A. foi a empresa que teve maior participação das variáveis econômicas na variação de seus custos proporcionais. As variáveis econômicas, explicaram mais de $70 \%$ da variação de seus custos proporcionais. Enquanto que na indústria BRF S.A. estas variáveis independentes explicaram 43\% da variação dos seus custos proporcionais, sendo esta, a indústria que apresentou a menor participação destas variáveis em todo o período analisado.

\section{CONSIDERAÇÕES FINAIS}

Esta pesquisa teve como objetivo verificar como o comportamento dos fatores econômicos da taxa de câmbio, taxa de juros e da inflação, influenciam na variação dos custos proporcionais de empresas do ramo alimentício, do setor de carnes e derivados, listadas na BOVESPA.

Para isso, inicialmente foram coletados os dados das variáveis econômicas da taxa de câmbio, representada pela moeda americana, o dólar, e da taxa de juros (SELIC), no site do BACEN; já a inflação acumulada anual, medida pelo IPCA, foi encontrada no site do IBGE. Tanto para o dólar, quanto para a SELIC, foi realizada a 
média anual dos valores encontrados. 0 período pesquisado foi do ano de 2003 a 2015. Em seguida fez-se a coleta dos dados documentais das empresas, através de suas demonstrações anuais, publicadas no site da BOVESPA. Foram verificadas nas DREs de cada empresa, o montante do CPV, bem como da receita líquida.

Posterior a coleta dos dados, foi calculado o custo proporcional de cada empresa, como também foi aplicado o método estatístico da regressão linear múltipla. Com a regressão linear múltipla empregada, foi possível encontrar o coeficiente de determinação de cada empresa, cujo valor pode variar de 0 a 1 , sendo que quanto mais próximo de 1, mais acurado é o resultado obtido entre as variáveis.

Para efetivação da análise foram considerad os os parâmetros atribuídos por Hair et al (2014) e Chin (1998). De acordo com Hair et al (2014) os valores de 0,75, 0,50 e 0,25 são considerados respectivamente substanciais, moderados e fracos. Enquanto que para o autor Chin (1998) os valores 0,67, 0,33 e 0,19 são considerados, respectivamente, substancial, moderado e fraco.

Foi observado que em todas as indústrias analisadas, segundo os parâmetros de Chin (1998), as variáveis econômicas possuem certa substância na relação as variações dos custos proporcionais. Os índices variaram entre 0,43 e 0,73 .

Já pelos parâmetros de Hair et al (2014), a indústria BRF S.A. foi a que teve seu custo proporcional menos influenciado pelas variações econômicas, com um R-quadrado de 0,43, que caracteriza uma influência moderada. As demais empresas tiveram resultados substanciais quanto à influência das variáveis em relação as variações dos custos.

As empresas em geral devem ficar atentas às variações econômicas, o que pode vir a ser um fator determinante para aumento ou redução dos custos, pois conforme comprovado pela pesquisa, a maioria das empresas analisadas são influenciadas substancialmente pelas variáveis econômicas em seus custos proporcionais. 


\section{REFERÊNCIAS}

BANCO CENTRAL DO BRASIL. Taxa de câmbio. Disponível em: <http://www.bcb.gov.br/?TAXCAMFAQ>. Acesso em: 24 fev. 2016 . maio 2016b.

Histórico das taxas de juros. Disponível em: <http://www.bcb.gov.br/?COPOMJUROS>. Acesso em: 15

Taxa Selic: conceito. Disponível em: <http://www.bcb.gov.br/htms/selic/conceito_taxaselic.asp>. Acesso em: 22 maio 2016c.

BEUREN, Ilse Maria. Evolução histórica da contabilidade de custos. Contabilidade Vista \& Revista. Belo Horizonte, v. 5, n. 1, p. 61-66, fev. 1993. Disponível em:

$<h t t p: / /$ revistas.face.ufmg.br/index.php/contabilidadevistaerevista/article/view/52/50>. Acesso em: 15 maio 2016.

BORNIA, Antônio Cezar. Análise gerencial de custos: aplicação em empresas modernas. Porto Alegre: Bookman, 2002

BOVESPA. Empresas listadas. Disponível em: <http://www.bmfbovespa.com.br/pt_br/produtos/listados-avista-e-derivativos/renda-variavel/empresas-listadas.htm>. Acesso em 20 fev. 2016.

BRUNI, Adriano Leal. A Administração de Custos, Preços e Lucros com Aplicações na Calculadora HP 12C e Excel. São Paulo: Atlas, 2006.

CAETANO, Sidney Martins; CORRÊA, Wilson Luiz Rotatori. A distribuição regional de inflação: uma análise para inflação mineira no período pós-Real. Seminário sobre a Economia Mineira, 7., 2006, Diamantina. Anais do XII Seminário sobre a Economia Mineira, Diamantina-MG, 2006, p. 1-23.

CERVO, Amado Luiz; BERVIAN, Pedro Alcino; SILVA, Roberto da. Metodologia Científica. 6. ed. São Paulo: Pearson Prentice Hall, 2007.

CHIN, Wynne W. Issues and opinions on SEM . Management Information Systems Quarterly, v.22, n.1, p. vii-xvi, mar.1998.

CREPALDI, Silvio Aparecido. Curso básico de contabilidade de custos. 5. ed. São Paulo: Atlas, 2010.

GIL, Antônio Carlos. Métodos e técnicas de pesquisa social. 5. ed. São Paulo: Atlas, 2002.

GREMAUD, Amaury Patrick; VASCONCELLOS, Marco Antonio Sandoval de; TONETO JÚNIOR, Rudinei. Economia brasileira contemporânea. 7. ed. São Paulo: Atlas, 2014.

HAIR, J oseph F. et al. A Primer on Partial Least Squares Structural Equation Modeling (PLS-SEM). LoS Angeles: SAGE, 2014.

INSTITUTO BRASILEIRO DE GEOGRAFIA E ESTATÍSTICA. Séries históricas. Disponível em: $<h t t p: / / w w w . i b g e . g o v . b r / h o m e / e s t a t i s t i c a / i n d i c a d o r e s / p r e c o s / i n p c \_i p c a / d e f a u l t s e r i e s H i s t . s h t m>$. Acesso em 04 jun. 2016.

LANZANA, Antonio Evaristo Teixeira. Economia brasileira: fundamentos e atualidades. 2. ed. São Paulo: Atlas, 2002

MARTINS, Eliseu. Contabilidade de custos. 10. ed. São Paulo: Atlas, 2010.

MENDONÇA, Helder Ferreira de. Metas de inflação e taxa de juros no Brasil: uma análise do efeito dos preços livres e administrados. Revista de Economia Política, v. 27, p. 431-451, 2007. Disponível em: <http://www.scielo.br/pdf/rep/v27n3/v27n3a07>. Acesso em 27 jan. 2018.

MICHEL, Maria Helena. Metodologia e pesquisa científica em ciências sociais. São Paulo: Atlas, 2005. 
MONTGOMERY, Douglas C.; RUNGER, George C. Estatística aplicada e probabilidade para engenheiros. 5. ed. Rio de Janeiro: LCT, 2012.

OLIVEIRA, Luíz Martins de; PEREZ JUNIOR, J osé Hernandez. Contabilidade de custos para não contadores. São Paulo: Atlas, 2000.

OLIVEIRA, Marcelo Silva de et al. Introdução à estatística. Lavras: UFLA, 2014.

OMAR, Jabr H. D. Taxa de juros: comportamento, determinação e implicações para a economia brasileira.

Revista de Economia Contemporânea, v. 12, n. 3, p. 463-490. 2008. Disponível em:

$<$ http://www.scielo.br/pdf/rec/v12n3/03.pdf>Acesso em: 23 abr. 2016.

PASSOS, Carlos Roberto Martins; NOGAMI, Otto. Princípios de economia. 5. ed. rev. São Paulo: Cencage Learning, 2010.

PAULA, L. F. R. Tamanho, dimensão e concentração do sistema bancário no contexto de alta e baixa inflação no Brasil. Nova Economia, v. 8, n. 1, p. 87-116, 1998. Disponível em:<http://www.revistas.face.ufmg.br/index.php/novaeconomia/article/download/2236/1178> Acesso em: 27 jan. 2018.

RICHARDSON, Roberto J arry. Pesquisa social: métodos e técnicas. 3. ed. São Paulo: Atlas, 1999.

SERRANO, Franklin. Relações de poder e a política macroeconômica americana de Bretton Woods ao padrão dólar flexível. In: FIORI, J osé Luís (Org.). 0 poder americano. Petrópolis: Vozes, 2004, p. 190-204.

SILVA JUNIOR, José Barbosa da et al. Custos: ferramenta de gestão. 5. ed. São Paulo: Atlas, 2000.

SOARES, Pedro. PIB fica estagnado em 2014, com alta de 0,1\%, pior resultado desde 2009. Folha de São Paulo, São Paulo, 27. mar. 2015. Disponível em: <http://www 1.folha.uol.com.br/mercado/2015/03/1608985-pib-cresce01-em-2014-aponta-ibge.shtml>. Acesso em: 14 maio 2016.

THEÓPHILO, Carlos Renato; MARTINS, Gilberto de Andrade. Metodologia da investigação científica para ciências sociais aplicadas. 3. ed. São Paulo: Atlas, 2016.

VASCONCELLOS, Marco Antonio Sandoval de. Economia micro e macro. 5. ed. São Paulo: Atlas, 2011.

VASCONCELLOS, Marco Antonio Sandoval de; GARCIA, Manoel Enriquez. Fundamentos de economia. 2. ed. São Paulo: Saraiva, 2006.

VERGARA, Sylvia Constant. Projetos e relatórios de pesquisa em administração. 5. ed. São Paulo: Atlas, 2004.

WALPOLE, Ronald E. et al. Probabilidade e estatística para engenharia e ciências. 8. ed. São Paulo: Afiliada, 2010. 